\title{
Value Of Multi-Family Housing
}

\author{
Peter F. Colwell* and C. F. Sirmans**
}

\section{INTRODUCTION}

The urban economics literature on the market value of housing has expanded rapidly in recent years. Most of this literature, however, has been concerned with single-family housing with little theoretical and empirical work on the value of multi-family housing $[1 ; 3 ; 4 ; 10]$. The purpose of this paper is to examine this neglected aspect of the urban economics literature. Urban economists as well as real estate practitioners are prone to thinking of market value as being proportional to gross income $[7$, p. $165 ; 6]$. While the gross income multiplier concept has had a place in the urban land economics literature since at least the 1930's, only relatively recently have studies been concerned with an empirical analysis $[9,12]$. This empirical work has used a simple linear regression model while the theoretical foundations have been ignored.

This paper develops a model which relates a theory of the housing firm's behavior to the concept of a gross income multiplier. This model provides insights into whether rational behavior leads to the existence of a gross income multiplier and the functional form of the market value-gross income relationship. The analysis indicates that the widely accepted proportional and previously utilized linear forms are inappropriate. Furthermore, the non-linear form suggested by the theoretical model proves to be empirically superior.

\section{A THEORETICAL FRAMEWORK}

In this section a model is developed which provides some theoretical justification for the selection of a particular form for the value-income function. This model is at the dwelling unit or apartment level. It is not at the apartment building level. Housing services $(\mathrm{H})$ are produced by housing stock (h) and operation (L) as in "operation and maintenance." The model assumes competition in that the prices of housing services (p), housing stock $(\rho)$, operation (w), and credit (i) are assumed to be determined in their respective markets and are unaffected by decisions at the level of a single dwelling unit.

The construction of this model begins by specifying a production function. Next, the short-run profit maximizing levels of the operation $(\mathrm{L})$ and

\footnotetext{
*Department of Finance, College of Business Administration, University of Illinois, Urbana, Illinois 61801 **Department of Real Estate, College of Business Administration, University of Georgia, Athens, Georgia 30602.
} 
housing services $(\mathrm{H})$ are found as functions of the housing stock $(\mathrm{h})$. These functions, in turn, make it possible to derive property value (i.e., the discounted stream of net income) as a function of the housing stock. Assuming that landlords are wealth maximizers, the housing stock which they consider to be optimal maximizes the difference between property value and the cost of housing stock. Finally by substituting the expression for optimal stock into the function which relates value to the stock, a function is obtained which relates market value (i.e., the value assuming efficient management in the short and long run including the optimal choice of housing stock) to the optimal gross income. Assuming that variation in market value and optimal gross income arises from variation in certain prices and parameters in the model, it is possible to sketch the shapes of the resultant value-income functions.

The dwelling unit's production function is assumed to be of the CobbDouglas type with diminishing returns to scale. That is,

$$
\mathrm{H}=\tau \mathrm{h} \zeta_{\mathrm{L}} \xi \text { where } \zeta>0, \xi>0 \text {, and } \zeta+\xi<1 .
$$

Given the level of housing stock in the short-run, the owner of the dwelling unit would select a level of operation which would equate the price of operation (w) with the value of its marginal product. Thus the shortrun profit maximizing level of operation ( $\hat{\mathrm{L}})$ may be found as follows:

$$
\mathrm{w}=\mathrm{p} \xi \tau \mathrm{h} \zeta \hat{\mathrm{L}} \xi-1 \text {, and } \hat{\mathrm{L}}=\left[\frac{\mathrm{w}}{\mathrm{p} \xi \tau}\right]^{\frac{1}{\xi-1}} \mathrm{~h}^{\frac{\zeta}{-\xi-1}} \text {. }
$$

Substituting the short-run profit maximizing level of operation (2) into the production function (1), the short-run profit maximizing level of housing services $(\mathrm{H})$ is obtained.

$$
\hat{\mathrm{H}}=\tau \mathrm{h} \quad-\frac{\zeta}{\xi-1} \frac{\mathrm{w}}{\mathrm{p} \xi \tau} \frac{\zeta}{\xi-1}
$$

Net income is simply gross income $(\mathrm{p} \hat{\mathrm{H}})$ minus the cost of operation $(w \hat{\mathbf{L}})$ and maintenance. In order to determine the cost of maintenance, it is necessary to know the amount of depreciation (i.e., the real erosion of the stock's productive capacity) each period. It is assumed that depreciation is a constant proportion $(\delta)$ of the housing stock. This proportion is determined exogenously. Thus the cost of maintenance is the price of housing stock $(\rho)$ multiplied by the amount that depreciates $(\delta \mathrm{h})$. So the cost of maintenance is a constant proportion of the stock which is maintained and the constant of proportionality is $\rho \delta$.

Assuming that the dwelling unit owner expects constant real prices in the future, his assessment of the present value of net income is as follows:

$$
\mathrm{V}=[\mathrm{p} \hat{\mathrm{H}}-\mathrm{w} \hat{\mathbf{L}}-\rho \delta \mathrm{h}] / \mathrm{i}
$$


where $i$ is the price of credit and the owner's discount rate. Substituting (2) and (3) into (4) shows that value is a strictly concave function of housing stock. This is because the power on $h$ in equation (5) is positive but less than unity as a result of the production function having diminishing returns to scale.

$$
\mathrm{V}=\frac{\mathrm{p} \tau \frac{\mathrm{w}}{\mathrm{p} \xi \tau} \frac{\xi}{\xi-1}^{\frac{\xi}{\mathrm{p} \xi \tau}} \frac{\mathrm{w}}{\frac{1}{\xi-1}} \mathrm{~h}-\frac{\zeta}{\xi-1}}{\mathrm{i}}-\frac{\rho \delta \mathrm{h}}{\mathrm{i}} .
$$

On the other hand, the initial cost $(\mathrm{C})$ of achieving any level of stock (i.e., above $[1-\delta] \mathrm{h}_{0}$ ) is a linear function of stock, the slope of which is the price of housing stock.

$$
\mathrm{C}=-\rho \mathrm{h}_{\mathrm{o}}+\rho \mathrm{h} .
$$

This means that the cost is zero at the existing level of stock, $h_{0}$. At lower levels of stock, the cost is negative indicating that some amount of maintenance is avoided with disinvestment. That is, maintenance is less than depreciation so stock declines.

The net present value is the difference between the functions $\mathrm{V}$ and $\mathrm{C}$. The optimal stock, $\left(\mathrm{h}^{*}\right)$ is the one which maximizes the net present value. Taking the derivative of $\mathrm{V}-\mathrm{C}$ with respect to $\mathrm{h}$ and setting it equal to zero allows the solution for the optimal housing stock.

$$
\mathrm{h}^{*}=\mathrm{w}^{-\frac{\xi}{1-\zeta-\xi}}\left[\frac{\rho[\mathrm{i}+\delta]}{\frac{\zeta}{\xi-1}\left[\frac{1}{\xi \tau} \frac{1}{\xi-1}^{\frac{1}{\xi}}-\tau\left[\frac{1}{\xi \tau}\right] \frac{\xi}{\xi-1}\right] \mathrm{p}-\frac{1}{\xi-1}}\right]_{(7)}^{\frac{\xi-1}{1-\zeta-\xi}}
$$

or $\mathrm{h}^{*}=\mathrm{Xw}_{\mathrm{w}}-\frac{\xi}{1-\zeta-\xi}$ where $\mathrm{X}$ equals the right hand term in (7). By substituting (7) into (5), the value which maximizes net present value $\left(\mathrm{V}^{*}\right)$ is obtained.

$$
\mathrm{V}^{*}=\frac{\mathrm{i}+\delta-\xi \mathrm{i}-\xi \delta-\zeta \delta}{\mathrm{i}[\mathrm{i}+\delta]}[\text { gross income }]
$$

where gross income $=\tau\left[\frac{1}{\xi \tau}\right]^{\frac{\xi}{\xi-1}}[\mathrm{p}]^{-\frac{1}{\xi-1}}[\mathrm{x}]^{-\frac{\zeta}{\xi-1}}[\mathrm{w}]^{-\frac{\xi}{1-\zeta-\xi}}$

That this complicated expression is gross income can be verified by first substituting (7) into (3) and obtaining optimal housing services, then multiplying this result by $\mathrm{p}$, the price of housing services. This product of 
optimal housing services and the price of housing services is rent or gross income. The gross income multiplier $(\mathrm{m})$ is the left hand term in equation (8). That is,

$$
\mathrm{m}=\frac{\mathrm{i}+\delta-\xi \mathrm{i}-\xi \delta-\zeta \delta}{\mathrm{i}[\mathrm{i}+\delta]}
$$

Variations in parameters and prices across dwelling units give rise to variations in optimal stock and optimal gross income. If a parameter or price which is not found in the multiplier varies, the model suggests that there will be a proportional relationship between value and gross income, and the multiplier $(\mathrm{m})$ is the constant of proportionality. Thus if $\mathrm{w}$ or $\tau$ varies, gross income is affected, but the multiplier is not affected. In this case, the model appears to justify the most primitive appraisal practices utilizing the gross income multiplier.

On the other hand, suppose that gross income varies because of variations in $\delta$ or i. Both $\delta$ and i appear in the multiplier term in addition to being in the gross income term. Thus there will not be a proportional relationship between market value and gross income. For example, if $\delta$ increases, it is obvious that gross income decreases. However, it is not obvious that the multiplier also decreases.

$$
\frac{\partial \mathrm{m}}{\partial \delta}=-\frac{\zeta \mathrm{i}}{\mathrm{i}[\mathrm{i}+\delta]^{2}} .
$$

This suggests that market value increases at an increasing rate as gross income increases.

On the other hand, suppose that gross income varies across dwelling units because $\zeta$ varies. As $\zeta$ increases so does the optimal stock and the optimal gross income. However the multiplier decreases.

$$
\frac{\partial \mathrm{m}}{\partial \zeta}=-\frac{\delta}{\mathrm{i}[\mathrm{i}+\delta]} .
$$

This suggests that market value increases at a decreasing rate as gross income increases.

From the theoretical model developed in this section, it appears that the log-linear functional form should be used because of its capacity to capture any of these three possibilities for the value-income function: proportional, increasing-convex, or increasing-concave.

\section{FUNCTIONAL FORM ANALYSIS}

This section develops an empirical basis for the selection of a functional form to represent the market value-gross income relationship. Data on 206 sales of multi-family housing from three neighborhoods in Chicago are used which extend from 1963 to 1975. Of these, 84 sales are from Albany 
TABLE 1

Simple Market Value-Gross Income Function ${ }^{\mathrm{a}}$

\begin{tabular}{|c|c|c|c|}
\hline \multirow{2}{*}{$\begin{array}{l}\text { Independent } \\
\text { Variable }\end{array}$} & \multicolumn{3}{|c|}{ Neighborhood } \\
\hline & Albany Park & Rogers Park & Uptown \\
\hline \multicolumn{4}{|c|}{ Dependent Variable $=$ Market Value } \\
\hline CONSTANT & $\begin{array}{l}17140.22 \\
(1468.07)\end{array}$ & $\begin{array}{c}5425.87 \\
(2624.17)\end{array}$ & $\begin{array}{l}13995.8 \\
(2983.53)\end{array}$ \\
\hline Gross Income (GI) & $\begin{array}{c}3.30689 \\
(.07676)\end{array}$ & $\begin{array}{l}5.75110 \\
(.155808)\end{array}$ & $\begin{array}{l}2.42290 \\
(.098431)\end{array}$ \\
\hline$\overline{\mathrm{R}}^{2}$ & .957 & .955 & .913 \\
\hline \multicolumn{4}{|c|}{ Dependent Variable $=\ln ($ Market Value $)$} \\
\hline CONSTANT & $\begin{array}{l}4.99117 \\
(.159922)\end{array}$ & $\begin{array}{l}2.99690 \\
(.160346)\end{array}$ & $\begin{array}{l}3.87207 \\
(.310895)\end{array}$ \\
\hline $\log$ (Gross Income) & $\begin{array}{l}.64121 \\
(.017106)\end{array}$ & $\begin{array}{l}.87776 \\
(.017404)\end{array}$ & $\begin{array}{c}.72828 \\
(.032147)\end{array}$ \\
\hline $\mathrm{R}^{2}$ & .944 & .975 & .899 \\
\hline
\end{tabular}

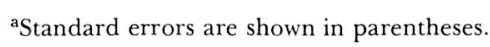

Park; 64 are from Rogers Park; and 58 are from Uptown. The buildings in the sample are generally similar in appearance in that they are unfurnished, two or three story walk-ups. They do, however, vary in size from 2 to 80 dwelling units, with 66 of the observations between 2 and 4 dwelling units, 49 between 5 and 9 , and 91 having 10 or more dwelling units. The market value-gross income relationship dealt with in this section is at the apartment house level rather than the dwelling unit level. There may be differences within neighborhoods but we do not control for this possible effect.

The regression results in Table 1 show that there is no gross income multiplier as conventionally conceived. The simple relationship between market value and gross income is not proportional. This can be seen by the constant terms in the top half of Table 1 being significantly different from zero at the $90 \%$ level of confidence. Thus the slopes of these linear functions cannot be interpreted as gross income multipliers; they express the marginal and not the average market value-gross income relationships.

Alternatively, one may question whether the linear functional form is appropriate. Table 1 also illustrates a non-linear form (i.e., linear in logs) which appears to fit the data in all three neighborhoods rather well. Still, this functional form (going through the origin so that zero income yields zero value) fails to save the crude gross income multiplier concept. This is shown by the magnitude of all three coefficients on LN GI. They are all 
significantly different from and less than 1 at the $90 \%$ level of confidence. Thus the function increases at a decreasing rate and the multiplier or the ratio of $\mathrm{V}$ to GI declines with GI.

It is important to discriminate between the linear and log linear functional forms in Table 1. Goodness-of-fit criteria are inappropriate since the dependent variable is different. Box and Cox (1964) have provided a technique to discriminate between the linear and log-linear forms. Several recent studies have used this functional form technique. See, for example, Kau and Sirmans (1979).

Assuming that the correct functional form of the value-income relationship belongs to the following simple-class of power transformations, and assuming that no relevant variables have been left-out, the function may be written:

$$
\mathrm{V}_{\mathrm{i}}^{\lambda}=\alpha+\beta(\mathrm{GI})^{\lambda}+\mu_{\mathrm{i}}
$$

when $V_{i}$ is the value of the $i^{\text {th }}$ building and $G_{i}$ is the gross income of the $i^{\text {th }}$ building and $\mu_{\mathrm{i}}$ is an error term of usual form.

Using the Box-Cox transformation procedure, (12) can be written as,

$$
\frac{\left(\mathrm{V}_{\mathrm{i}}\right)^{\lambda-1}}{\lambda}=\alpha^{\prime}+\beta^{\prime} \frac{\left(\mathrm{GI}_{\mathrm{i}}\right)^{\lambda-1}}{\lambda}+\mu_{\mathrm{i}}
$$

The $\lambda=1$ defines the simple linear transformation with all variables sequential by their natural values. When $\lambda=0$, equation (13) becomes the logarithmic-linear transformation. Thus the problem is to search for an optimal transformation. In applying the Box-Cox analysis, it is assumed that $\mu_{\mathrm{i}} \sim \mathrm{N}\left(0, \sigma^{2}\right)$ and that income is uncorrelated with the error term.

An optimal specification is selected by calculating the maximized likelihood function for alternative values of $\lambda$, except for a constant term, as,

$$
\mathrm{L}_{\mathrm{MAX}}(\lambda)=-\mathrm{N} / 2 \ln \hat{\sigma}^{2}(\lambda)+(\lambda-1) \sum_{\mathrm{i}=1}^{\mathrm{N}} \ln \mathrm{V}_{\mathrm{i}}
$$

where $\hat{\sigma}^{2}$ is the estimated variance of the regression of $V_{i}$ on $G_{i}$ for alternative $\lambda$ 's using equation (13) and $\mathrm{N}$ equals the sample size. After determining the maximizing value, $\lambda$, alternative values of $\lambda$ can be rejected using equation (4) to obtain a confidence interval:

$$
2\left[\mathrm{~L}_{\operatorname{MAX}}(\hat{\lambda})-\mathrm{L}_{\operatorname{MAX}}(\lambda)\right]<\chi_{1}^{2}(\alpha)
$$

where $\chi_{1}^{2}(\alpha)$ denotes the chi-squared statistic with 1 degree of freedom. When $\alpha=.05$, the $\chi_{1}^{2}$ value equals 1.92 .

Using the data for three neighborhoods in Chicago, equation (13) was estimated using $\lambda$ values from -.5 to 1.5 at intervals of . 1 . Thus 21 equations 
TABLE 2

Value of Multi-Family Housing ${ }^{\text {a }}$

\begin{tabular}{|c|c|c|c|}
\hline \multicolumn{4}{|c|}{ DEPENDENT VARIABLE ${ }^{b} \ln \mathrm{V} / \mathrm{U}$} \\
\hline & & Neighborhood & \\
\hline Variable & Albany Part & Rogers Park & Uptown \\
\hline CONSTANT & $\begin{array}{c}4.56232 \\
(.69870)\end{array}$ & $\begin{array}{l}1.59937 \\
(.33527)\end{array}$ & $\begin{array}{l}1.88365 \\
(1.0076)\end{array}$ \\
\hline $\operatorname{lnGI/U}$ & $\begin{array}{l}.697465 \\
(.096594)\end{array}$ & $\begin{array}{l}1.07638 \\
(.045736)\end{array}$ & $\begin{array}{c}1.01164 \\
(.13794)\end{array}$ \\
\hline YOS & $\begin{array}{l}.000145^{\mathrm{d}} \\
(.000505)\end{array}$ & $\begin{array}{r}-.000648 \\
(.000347)\end{array}$ & $\begin{array}{r}-.00181 \\
(.000747)\end{array}$ \\
\hline $\ln \mathrm{U}$ & $\begin{array}{r}-.35965 \\
(.02007)\end{array}$ & $\begin{array}{r}-.14914 \\
(.01630)\end{array}$ & $\begin{array}{r}-.22987 \\
(.03500)\end{array}$ \\
\hline $\mathrm{R}^{2}$ & .906 & .916 & .788 \\
\hline
\end{tabular}

aStandard errors are in parentheses.

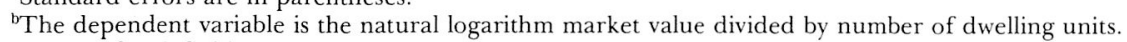

'See text for definitions of variables.

${ }^{\mathrm{d}}$ Not significantly different from zero.

result for each neighborhood. The $\mathrm{L}_{\mathrm{MAX}}(\lambda)$ for each of the neighborhoods was calculated using equation (14) and the results indicate that in each case the hypothesis that the linear form is correct can be rejected. The hypothesis that the log-linear form is correct cannot be rejected in each of the neighborhoods. These results imply that the simple linear model is a misspecification of the value-gross income function (Ratcliff, 1971; Shenkel, 1973).

\section{SOME EMPIRICAL EXTENSIONS}

In the theoretical section, it was demonstrated that the dwelling unit value-income function might be increasing-concave, increasing-convex, or proportional depending on the primary cause of income variability. In keeping with the theory, the econometric model developed in this section is at the dwelling unit level. Dwelling unit value is taken as a function of dwelling unit income, building scale or the number of dwelling units, and the year of sale. This model, by serendipity, reveals that each of the three neighborhoods in the study has a different shape for its value-income function.

As can be seen in Table 2, the coefficient on the natural log of gross income per dwelling unit ( $\ln \mathrm{GI} / \mathrm{u})$ is significantly greater than zero and significantly less than unity for Albany Park indicating the function is increasing and concave. The same coefficient is slightly but significantly greater than unity for Rogers Park indicating the function is increasing 
and convex. Finally, the coefficient is not significantly different from or greater than unity for the Uptown area indicating that there is a proportional relationship. All these tests of significance use the $90 \%$ level of confidence.

The coefficient on the year of sale (YOS) in the regressions reported in Table 2 may be interpreted as the annual rate of change in dwelling unit value, holding building scale and income constant. Although significant in two of the neighborhoods, Rogers Park and Uptown, the coefficients are very small. On the other hand, the number of units $(u)$ can be seen to have a strong inverse relationship with dwelling unit value in all three neighborhoods. Holding building scale constant by the inclusion of the number of units as an explanatory variable in the regression seems to be responsible for the variety of shapes exhibited by the partial value-income functions in Table 2. Thus, the concavity which is always found in the simple building value-income function should probably be attributed to variations in the parameters which are associated with variations in the number of dwelling units.

\section{CONCLUSIONS}

This paper deals with the determination of the market value of multifamily housing. Market value is related to gross income both theoretically and empirically. In Section 2, a theoretical model is developed which indicates that the shape of the dwelling unit level market value-gross income function depends on the reasons for income and value variation. For example, variation in certain parameters of the production function would cause the function to be concave whereas variation in others would cause it to be linear.

Utilizing the Box-Cox technique, the simple market value-gross income function is empirically demonstrated to be concave rather than linear, as has been assumed in other studies. This concavity of the simple market value-gross income function is largely attributed to differences in parameters associated with the number of units. This is shown by the fact that the partial relationship between market value and gross income is not necessarily concave when holding dwelling units constant.

\section{REFERENCES}

1. Ball, M., "Recent Empirical Work on the Determinants of Relative House Prices," Urban Studies, 10:213-234 (1973).

2. Box, G. E. P. and Cox, D. R., "An Analysis of Transformations," Journal of the Royal Statistical Society, Series B, 26:211-243 (1964).

3. Edelstein, R., "The Determinants of Value in the Philadelphia Housing Market: A Case Study of the Main Line 1967-1969," R. E. Stat., 56:319-328 (1974).

4. Kain, J. and Quigley, J., "Measuring the Value of Housing Quality," J.A.S.A., 65:532-548 (1970)

5. Kau, J. B. and Sirmans, C. F., "Urban Land Value Functions and the Price Elasticity of Demand for Housing," J.U.E., 6:112-121 (1979).

6. Main, J., "Waiting Out Profits in Rental Property," Money, 7:36-43 (1978).

7. Mills, E. S., Urban Economics. Glenview, Illinois: Scott, Foresmen and Company, 1972.
8. Shenkel, W. N., "Characteristics of Gross Income Multipliers," The Real Estate Appraiser, 39:23-30 (1968).

9. Shenkel, W. N., "New Concepts in Appraising Income-Producing Real Estate, The Real Estate Appraiser, 39:39-48 (1973).

10. Stewart, D. O., "The Effects of Differential Property Tax Rates on the Sales Prices of Single Family Residential Property," R. E. Stat., 60:150-153 (1978).

11. Ratcliff, R. U., "Don't Underrate the Gross Income Multiplier," The Appraisal Journal, 38:264-271 (1971).

12. Ratcliff, R. U., Current Practices in Income Property Appraisal-A Critique. Report \#30, Center for Real Estate and Urban Land Economics, Berkeley, California: University of California, 1967.

13. Wendt, P.F. The Appraisal of Real Estate-Review and Outlook. Athens, Georgia: University of Georgia Press 1975. 